\title{
Stable Bicyclic Functionalized Nitroxides: The Synthesis of Derivatives of Aza-nortropinone-5-Methyl-3-oxo-6,8- diazabicyclo[3.2.1]-6-octene 8-oxyls
}

\author{
Larisa N. Grigor'eva, Alexsei Ya. Tikhonov*, Konstantin A. Lomanovich and Dmitrii G. Mazhukin *D
}

check for updates

Citation: Grigor'eva, L.N.; Tikhonov, A.Y.; Lomanovich, K.A.; Mazhukin, D.G. Stable Bicyclic Functionalized Nitroxides: The Synthesis of Derivatives of Aza-nortropinone-5Methyl-3-oxo-6,8-diazabicyclo[3.2.1]6-octene 8-oxyls. Molecules 2021, 26, 3050. https://doi.org/10.3390/ molecules 26103050

Academic Editor: Mario Waser

Received: 20 April 2021

Accepted: 18 May 2021

Published: 20 May 2021

Publisher's Note: MDPI stays neutral with regard to jurisdictional claims in published maps and institutional affiliations.

Copyright: (c) 2021 by the authors. Licensee MDPI, Basel, Switzerland. This article is an open access article distributed under the terms and conditions of the Creative Commons Attribution (CC BY) license (https:/ / creativecommons.org/licenses/by/ $4.0 /)$.
N.N. Vorozhtsov Novosibirsk Institute of Organic Chemistry SB RAS, Academician Lavrentiev Ave. 9 , 630090 Novosibirsk, Russia; lng@nioch.nsc.ru (L.N.G.); lomanovich@nioch.nsc.ru (K.A.L.)

* Correspondence: alyatikh@nioch.nsc.ru (A.Y.T.); d-mazhukin@yandex.ru (D.G.M.); Tel.: +7-383-330-8867 (A.Y.T.); +7-383-330-6852 (D.G.M.)

\begin{abstract}
In recent decades, bicyclic nitroxyl radicals have caught chemists' attention as selective catalysts for the oxidation of alcohols and amines and as additives and mediators in directed $\mathrm{C}-\mathrm{H}$ oxidative transformations. In this regard, the design and development of synthetic approaches to new functional bicyclic nitroxides is a relevant and important issue. It has been reported that imidazo[1,2$b$ ]isoxazoles formed during the condensation of acetylacetone with 2-hydroxyaminooximes having a secondary hydroxyamino group are recyclized under mild basic catalyzed conditions to 8-hydroxy5-methyl-3-oxo-6,8-diazabicyclo[3.2.1]-6-octenes. The latter, containing a sterically hindered cyclic $N$-hydroxy group, upon oxidation with lead dioxide in acetone, virtually quantitatively form stable nitroxyl bicyclic radicals of a new class, which are derivatives of both 2,2,6,6-tetramethyl-4oxopiperidine-1-oxyl (TEMPON) and 3-imidazolines.
\end{abstract}

Keywords: bicyclic nitroxide; condensation; acetylacetone; base-catalyzed recyclization; 3-imidazoline nitroxide; TEMPON; 8-hydroxy-5-methyl-3-oxo-6,8-diazabicyclo[3.2.1]-6-octene

\section{Introduction}

Among various types of organic radicals, nitroxyl radicals (NRs) are the most stable, most robust, and best-studied class of paramagnetic species. In addition to numerous publications on their synthesis and properties [1-9], more and more reports include numerous examples of their use. Thus, NRs are actively employed as oxidants and as trapping reagents in synthetic chemistry [10], as ligands in metal complex catalysis [11], as agents in nitroxide-mediated radical polymerization [12], as molecular spin probes [13], and spin labels [14] and in many other applications [15,16].

In the last decade, new areas of the use of nitroxides have been actively developing. For instance, NRs can participate in UV_-or visible-light-excited photosynthesis owing to their ability to participate in light-induced hydrogen atom transfer processes [17-19]. A popular NR, 2,2,6,6-tetramethylpiperidine 1-oxyl (TEMPO), has been employed as a mediator for obtaining $N$-centered radicals during electrosynthesis. For example, TEMPOmediated electrolysis of anilides or ketoximes generates amidyl or iminoxy radicals that trigger subsequent cyclization via an interaction of the forming radical with an unsaturated part of the molecule thereby leading to the closure of a pyrroline-type structure or cyclic nitrone [20]. With a sterically more hindered dispirocyclic NR under the conditions of electrochemical synthesis from sodium azide, it is possible to generate an azidyl radical, which at low temperatures can react twice with alkenes thus implementing alkene diazidation [21]. Taking into account all these "old" and new abilities of stable NRs, it seems worthwhile to direct our efforts toward the design and synthesis of new classes of functional nitroxides that may find applications in various modern fields of materials chemistry and biology. 
Bicyclic NRs (BNRs) have been known for a long time, starting from the 1960s (Figure 1, structures $\mathbf{A}-\mathbf{G}$ ); however, their active use as catalysts for the oxidation of alcohols, in particular, those containing a sterically hindered hydroxyl group, began relatively recently [22-26]. Other functional groups-primary amines [27], diols [28], and cyclic carbamates [29] — as it turned out, are also prone to oxidative transformations in the presence of BNR mediators, forming nitriles and lactone derivatives. Moreover, BNRs were recently shown to be superior additives for enantioselective Ni-catalyzed diarylation of vinylarenes [30] and as mediators for electrochemical $\alpha$-cyanation of secondary piperidines, morpholine, and pyrrolidine [31].

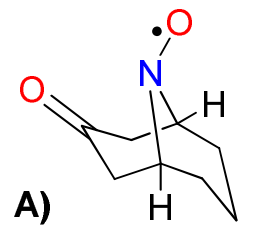

E)<smiles></smiles>

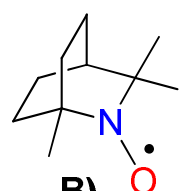

B)

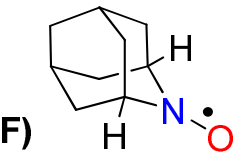

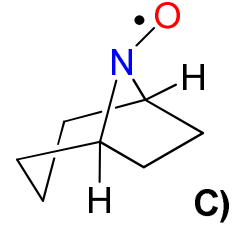

G)

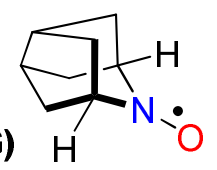

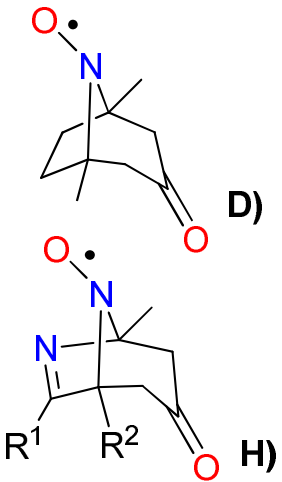

Figure 1. Selected examples of known BNRs: (A) Norpseudopelleterine N-oxyl [32]; (B) trimethylisoquinuclidine $N$-oxyl [33]; (C) nortropane $N$-oxyl [34]; (D) dimethylnortropinone $N$-oxyl [35]; (E) 9azabicyclo[3.3.1]nonane $N$-oxyl (ABNO) [36]; (F) 2-azaadamantane $N$-oxyl (AZADO) [37]; and (G) 9-azanoradamantane N-oxyl (nor-AZADO) [38]. (H) The BNRs obtained in this work.

In the present work, we report the first synthesis of BNRs that are derivatives of 5-methyl-3-oxo-6,8-diazabicyclo[3.2.1]-6-octene 8-oxyl, combining 2,2,6,6-tetramethyl-4oxopiperidine-1-oxyl (TEMPON) and 3-imidazoline NR moieties (Figure 1, structure $\mathbf{H}$ ).

This paper is a tribute to Professor Leonid B. Volodarsky who was the founder of the school of stable NRs of the imidazoline series and has inspired our research by his brilliant ideas for over 40 years.

\section{Results}

\subsection{The Synthesis of Bicyclic Nitroxides}

Previously, it has been demonstrated that the reaction of acetylacetone with 2-hydroxyamino oximes having a hydroxyamino group at the secondary carbon atom, 1a-d, proceeds through a number of intermediates in tautomeric equilibrium with each other and finally leads to derivatives of tetrahydroimidazo[1,2-b]isoxazoles 2a-d [39]. Refluxing of the latter in aqueous alkali is accompanied by the loss of a water molecule followed by recyclization, which entails the opening of the five-membered heterocycle and the formation of a six-membered tetrahydropyridine derivative (cyclic enaminoketone $\mathbf{3 a}-\mathbf{d}$ ) as the main product and 3-acetyl-1-hydroxypyrrole $4 \mathbf{a}-\mathbf{d}$ as a minor product. We found that this alkali-catalyzed reaction for compounds $\mathbf{2 a}, \mathbf{c}, \mathbf{d}$ under much milder conditions (cooling at $0-5{ }^{\circ} \mathrm{C}, 3-4 \mathrm{~h}$ ) yields a completely different result: bicycle 5 becomes the main product. Its structure was proved on the basis of spectral and analytical data. For instance, IR spectra of compounds $\mathbf{5 a , c , d}$ (in $\mathrm{KBr}$ ) contain intense bands at 1714-1716 and $1629-1639 \mathrm{~cm}^{-1}$, corresponding to stretching vibrations of isolated $\mathrm{C}=\mathrm{O}$ and $\mathrm{C}=\mathrm{N}$ bonds, as well as a band at $3600 \mathrm{~cm}^{-1}$ (in $\mathrm{CHCl}_{3}$ ), corresponding to the presence of an $\mathrm{OH}$ group. Compounds $\mathbf{5 a}, \mathbf{c}, \mathbf{d}$ do not have absorption maxima in the UV spectrum above $220 \mathrm{~nm}$, indicating the absence of a nitrone group or a conjugated system of unsaturated moieties in the molecule. Analysis of their ${ }^{1} \mathrm{H}$ and ${ }^{13} \mathrm{C}$ NMR spectra points to the existence of bicycle 5 in the form of a mixture of three isomers, one of which is cyclic hemiacetal $5 \mathrm{C}$ and the other two are the respective hydroxyamino derivatives in which the $\mathrm{N}-\mathrm{OH}$ bond is oriented either toward the keto 
group (compound 50-cis) or away from it (compound 5O-trans) (Scheme 1). Accordingly, in the PMR spectra of compounds $\mathbf{5 a , c , d}$ in a weak field, three distinct broadened signals are observed (at 7.45-7.54, 7.88-7.92, and 8.29-8.33 ppm), corresponding to protons of the $\mathrm{C}-\mathrm{OH}$ group of the hemiacetal and $\mathrm{N}-\mathrm{OH}$ protons for isomers $5 \mathrm{O}$-cis and 50-trans. The ratio of these species is shifted toward the prevailing, hypothetically, 50-trans conformation (47-65\%), while the proportion of $5 \mathrm{C}$ is $22-44 \%$, and the minor component is always 5O-cis (1-13\%). This structural assignment is confirmed by the ${ }^{13} \mathrm{C}$ NMR spectra of bicycles $5 \mathrm{a}, \mathrm{c}, \mathrm{d}$, in which carbonyl $\mathrm{C}$ atoms for 50-cis and 50-trans isomers are clearly distinguished at $\sim 206$ and $207 \mathrm{ppm}$, whereas the unique quaternary carbon atom of 5C, linked to two oxygen atoms, appears at 114 ppm (Supplementary Materials, Figures S1-S6).

a: $\mathrm{R}^{1,2}=\mathrm{Me}$

b: $\mathrm{R}^{1}=\mathrm{Ph}, \mathrm{R}^{2}=\mathrm{Me}$

c: $\mathrm{R}^{1+2}=\left(\mathrm{CH}_{2}\right)_{4}$

d: $\mathrm{R}^{1+2}=\left(\mathrm{CH}_{2}\right)_{5}$<smiles>[R]c1c(C(C)=O)c(C)n(O)c1[R]</smiles>

4a-d<smiles>[R]C1([R])NC(C)=CC(=O)CC/C1=N\O</smiles>

3a-d

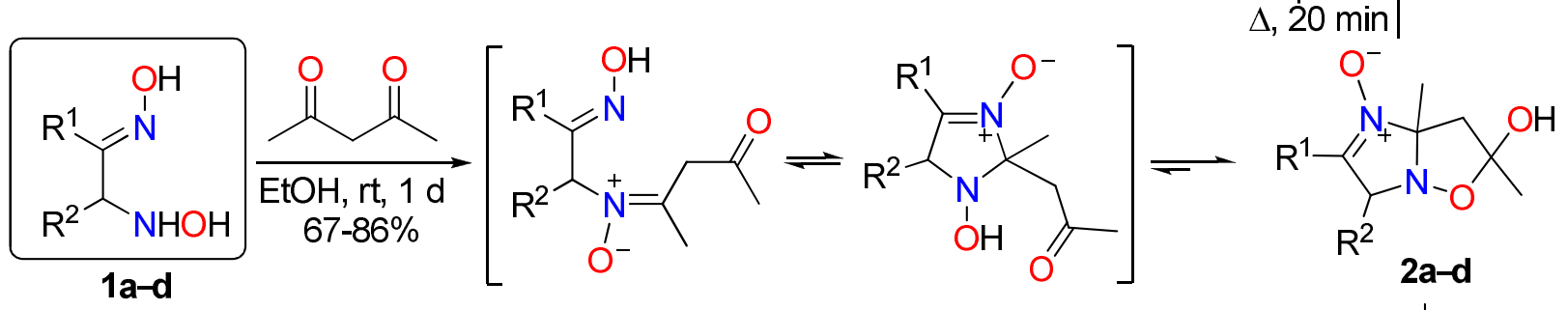

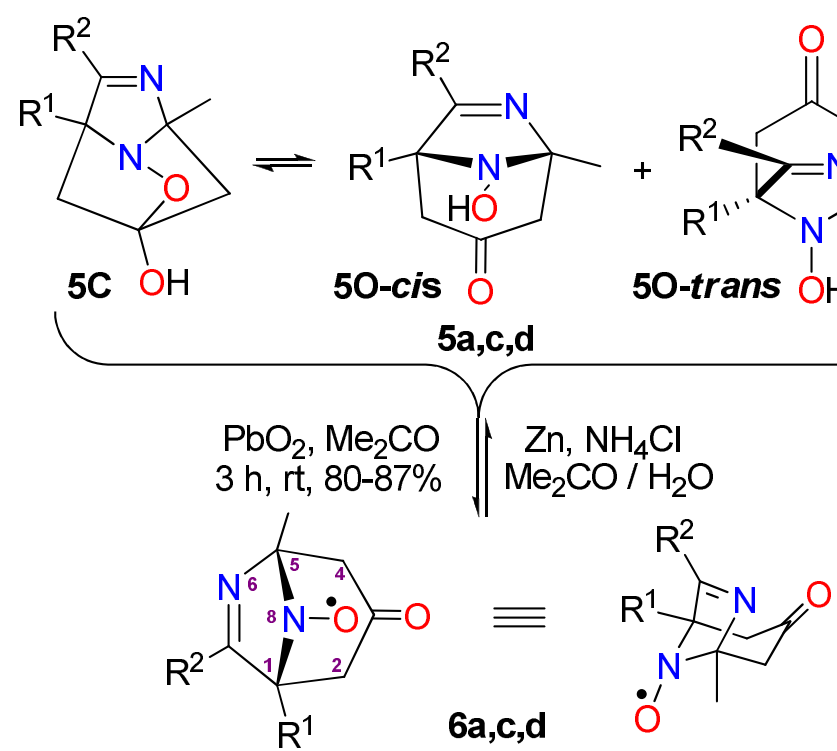

Scheme 1. Interaction of 2-hydroxyamino oximes 1a-d with acetylacetone and base-mediated transformations of imidazo[1,2b]isoxazoles 2a-d.

We found that bicycle 5 , encumbered with a sterically hindered $\mathrm{N}-\mathrm{OH}$ group, can be oxidized by lead dioxide to form a stable NR $(\mathbf{6 a}, \mathbf{6 c}$, or $\mathbf{6 d})$ as the only reaction product. Acetone is a solvent of choice for the preparation of BNRs; in this case, the yields of compounds $\mathbf{6 a}, \mathbf{c}, \mathbf{d}$ could reach $80-87 \%$ (Scheme 1). It should be noted that to achieve the highest yield of the radical, pure recrystallized samples of bicycle 5 should be used because the presence of impurities in the substrate affects the stability of 6 during its 
isolation, namely, during the concentration of the reaction solution. BNRs $\mathbf{6 a , c , d}$ are solid purple fine-crystalline compounds stable for a long time in a solid state in ambient air at room temperature in the dark. The radicals are readily soluble in polar organic solvents and organochlorides and relatively well soluble in water; for example, the solubility of BNR $6 \mathbf{c}$ at ambient temperature is $\sim 2.5 \times 10^{-2} \mathrm{M}$. Their IR spectra resemble those of their diamagnetic precursors, except that the band at $>3100 \mathrm{~cm}^{-1}$ is absent due to vibrations of the $\mathrm{N}-\mathrm{OH}$ group.

In the mass spectra of BNRs 6, along with the molecular ion peak at 181 (6a), 207 (6c), or 221 (6d), $M+1$ ions are present, and the most intense peak belongs to the $M-30$ ion corresponding to a loss of the N-O group (Supplementary Materials).

To confirm the structure of the obtained BNRs 6, they were reduced to their diamagnetic precursors 5 via a reaction with zinc powder in the presence of $\mathrm{NH}_{4} \mathrm{Cl}$ in aqueous acetone.

\subsection{EPR Study of New Bicyclic Nitroxides 6}

The EPR spectra of BNRs 6 recorded for degassed solutions in toluene represent triplets with hyperfine coupling $(h f c)$ constant $\mathrm{a}_{\mathrm{N}}$ of $\sim 1.855 \mathrm{mT}$, for one of which (radical 6c), a fine structure is observed due to the presence of a hyperfine interaction with hydrogen atoms in the $\mathrm{CH}_{2}{ }^{-}$and $\mathrm{CH}_{3}{ }^{-}$groups (Figure 2).

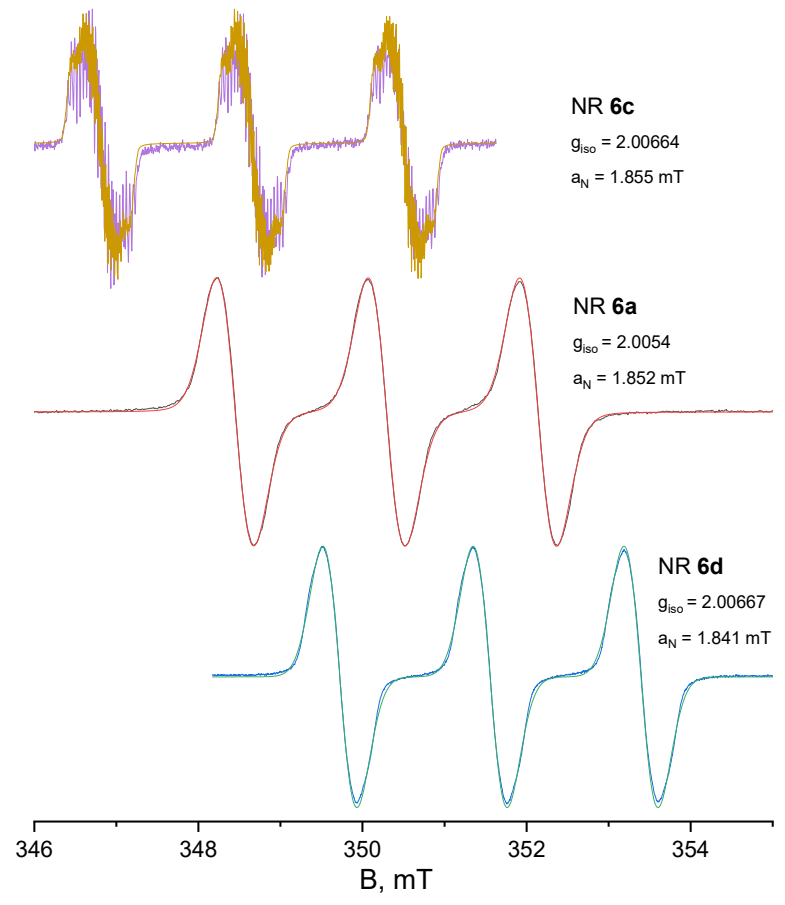

(A)

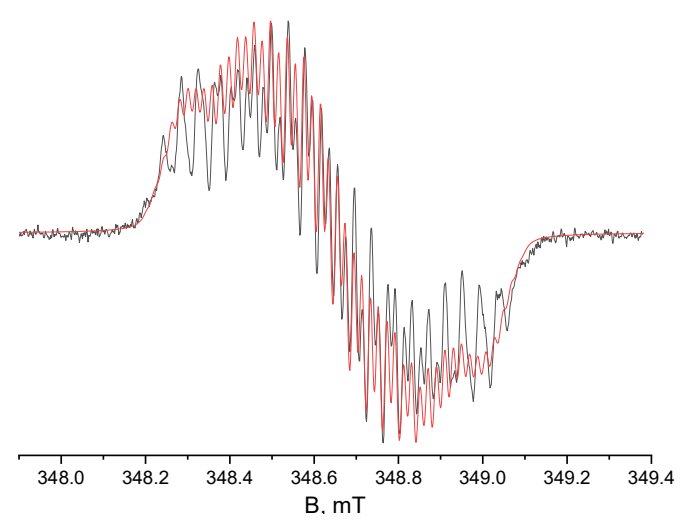

(B)

Figure 2. (A) EPR spectra of new bicyclic nitroxides, from the top: radicals $\mathbf{6 c}$, $\mathbf{6 a}$, and $\mathbf{6 d}$. (B) The center line in the spectrum of NR 6c. The black line: experimental spectrum, red line: mathematical reconstruction.

A similar splitting of the triplet has been documented earlier by Rassat et al. for the NR series of nortropinone (Figure 1, structure D), in which the hydrogen atoms located on the $\alpha$ - and $\alpha^{\prime}$-carbon atoms of the carbonyl group (C-2,4) interact with an unpaired electron, with the $\mathrm{a}_{\mathrm{H}}$ constant of $0.25 \mathrm{mT}(2 \mathrm{H})$ or $0.12 \mathrm{mT}(2 \mathrm{H})$ depending on whether they are in the axial or equatorial position of the six-membered ring [35]. In our case, due to the asymmetry of all carbon atoms in $\mathbf{6 c}$, the $h f c$ constants for all the different types of hydrogen atoms differ from each other and are in the range from 0.095 to $0.217 \mathrm{mT}$ for methylene protons in the carbonyl and decrease from $0.054 \mathrm{mT}$ for protons of the $\mathrm{CH}_{2}$ group on the six-membered ring closest to the radical center down to $\sim 0.001 \mathrm{mT}$ for the most distant protons of the aliphatic ring (Supplementary Materials, Figure S14). 
To the best of our knowledge, such BNRs containing both structural fragments of 2,5-dihydroimidazole and 4-piperidone have not been described previously in the literature. There is only one known example of the formation of bicyclic 1-hydroxy-3-imidazoline 3-oxide 7, which is carried out via the cyclodimerization of 3-methylbut-3-en-2-one oxime 8 with a low yield upon extra-long heating in a sealed ampoule, presumably through tetrahydropyridine intermediate $\mathbf{9}$ (Scheme 2) [40]. Although the putative structure of compound 7 has been confirmed by X-ray diffraction data [41], later, German researchers found that most of the reactions of bicyclic 7 proceed through the monocyclic tautomeric form of methylnitrone 10 [42]. They also showed that during the oxidation of solutions of $\mathrm{N}$-hydroxy derivative 7 in various polar and nonpolar solvents by $\mathrm{Ag}_{2} \mathrm{O}, \mathrm{PbO}_{2}$, hydrogen peroxide, or tert-butoxy or benzoyloxy radicals, the corresponding BNR 11 is generated with a typical $\mathrm{a}_{\mathrm{N}}$ of $1.9 \mathrm{mT}$ and an isotropic g-factor ( $\mathrm{g}_{\text {iso }}$ ) of 2.0058-2.0066 [43]. Nevertheless, the publications just cited do not say how stable the nitroxide $\mathbf{1 1}$ prepared in an EPR spectrometer ampoule is.

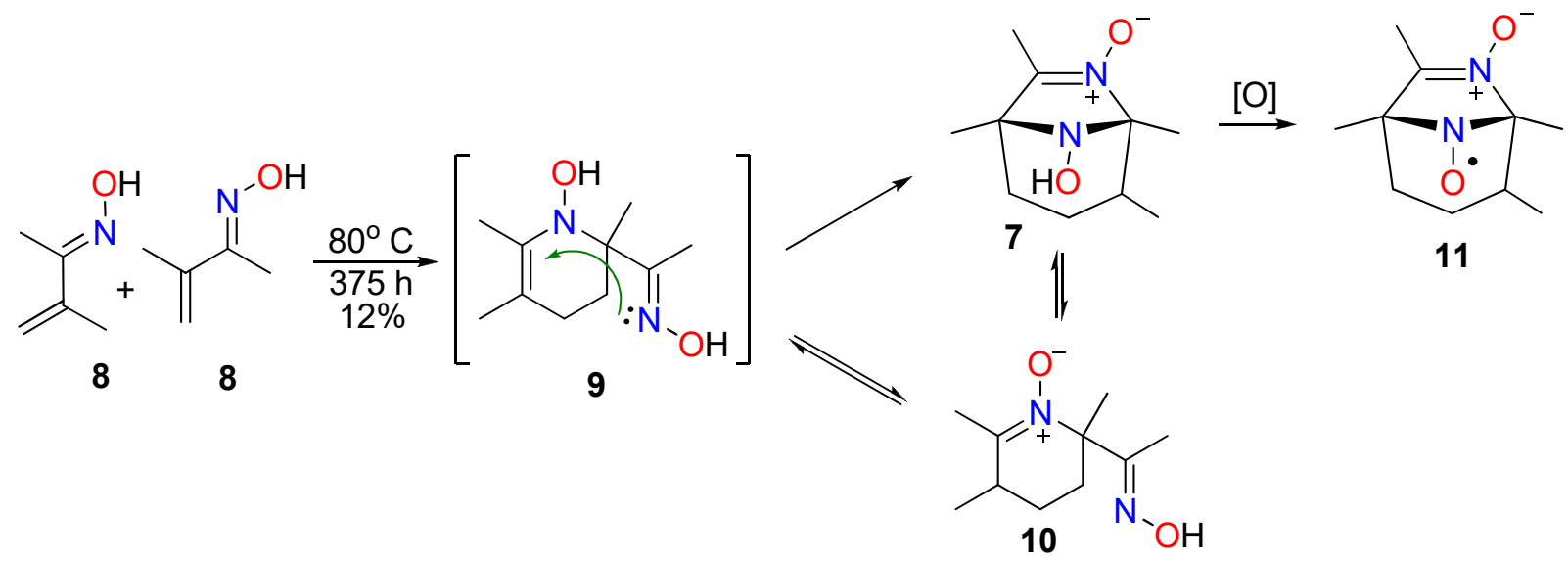

Scheme 2. Formation of 8-hydroxy-1,4,5,7-tetramethyl-6,8-diazabicyclo[3.2.1] oct-6-ene 6-oxide 7 via cyclodimerization of unsaturated oxime 8 .

According to our observations and similar data in the literature, now we can propose a mechanism of base-catalyzed recyclization of imidazoisoxazoles 2 . The mechanism consists of the transformation of $\mathbf{2}$ into an intermediate ( $2 \mathrm{H}$-imidazole $\mathrm{N}$-oxide $\mathbf{2} \mathbf{H}$-Im; Scheme 1 ), whose subsequent intramolecular interaction with the enolate anion generated in the reaction can occur both at the carbon atom of the nitrone group and at the carbon atom of the imino group, thus leading either to the product of kinetic control (bicyclic hydroxylamine 5 in the former case) or to the product of thermodynamic control (4-pyridone-2-ketoxime 3 in the latter case). Indeed, in the control experiment, when we introduced a crystallized sample of bicycle $5 \mathrm{~d}$ into the reaction, with short heating $\left(60-65^{\circ} \mathrm{C}\right)$ of this aqueous solution in $0.25 \mathrm{~N} \mathrm{NaOH}, \mathbf{5} \mathbf{d}$ virtually quantitatively turned into a single product, pyridone 3d, which was isolated and characterized by NMR spectroscopy.

\section{Materials and Methods}

\subsection{General Information}

Fourier transform infrared spectra (FT-IR) were recorded in $\mathrm{KBr}$ pellets on a Bruker Vector-22. UV-Vis spectra were obtained for EtOH solutions of bicyclic nitroxides $\mathbf{6 a}, \mathbf{c}, \mathbf{d}$ using a Hewlett-Packard HP 8453 spectrophotometer. ${ }^{1} \mathrm{H}$ NMR and ${ }^{13} \mathrm{C}$ NMR spectra were recorded on Bruker AV-300, AV-400, DRX-500, and AV-600 spectrometers at $300 / 400 / 500 / 600$ and $75 / 100 / 125 / 150 \mathrm{MHz}$, respectively, for 3-10\% solutions of compounds 2,3 , and 5 in DMSO- $d_{6}$; the positions of signals were determined relative to a residual proton signal [DMSO- $d_{6}(2.50 \mathrm{ppm})$ for ${ }^{1} \mathrm{H}$ spectra] or a carbon signal [DMSO- $d_{6}$ (39.4 ppm) for ${ }^{13} \mathrm{C}$ spectra] of the deuterated solvent. The analyses were performed on a Thermo Scientific DFS (Double Focusing System) high-resolution mass spectrometer 
(Thermo Electron Corp., Waltham, MA, USA); the recording mode was electron ionization with an ionizing electron energy of $70 \mathrm{eV}$, and exact mass was measured relative to the lines of the standard perfluorokerosene.

Elemental analyses were carried out on a Euro EA 3000 automatic CHNS analyzer. Melting points were determined by means of an FP 81 HT instrument (Mettler Toledo, Columbus, $\mathrm{OH}, \mathrm{USA})$. Column chromatography and thin-layer chromatography (TLC) were conducted using Acros silica gel 60A (0.035-0.070 mm) and Sorbfil PTLC-AF-UV 254 (Imid, Krasnodar, Russia), respectively, with eluents EtOAc and $\mathrm{CHCl}_{3}-\mathrm{MeOH}$.

EPR spectra of nitroxides $\mathbf{6 a}, \mathbf{c}, \mathbf{d}$ were acquired by means of a Bruker Elexsys E540 X-band continuous-wave EPR spectrometer at $295 \mathrm{~K}$ for diluted $\left(10^{-4} \mathrm{M}\right)$ and oxygen-free toluene solutions. Experimental settings for $\mathbf{6 c}$ were as follows: microwave power, $0.63 \mathrm{~mW}$; modulation frequency, $100 \mathrm{kHz}$; modulation amplitude, $0.002 \mathrm{mT}$; the number of points, 2048; sweep magnetic field, $6 \mathrm{mT}$; the number of scans, 160; and the time constant, $20 \mathrm{~ms}$. Experimental settings for $\mathbf{6 a}, \mathbf{d}$ were as follows: microwave power, $2.0 \mathrm{~mW}$; modulation frequency, $100 \mathrm{kHz}$; modulation amplitude, $0.05 \mathrm{mT}$; the number of points, 1024; sweep magnetic field, $10 \mathrm{mT}$; the number of scans, 8 ; and the time constant, $20 \mathrm{~ms}$. The following experimental settings for the center line of $6 \mathrm{c}$ were applied: microwave power, $0.63 \mathrm{~mW}$; modulation frequency, $100 \mathrm{kHz}$; modulation amplitude, $0.002 \mathrm{mT}$; the number of points, 1048; sweep magnetic field, $1.5 \mathrm{mT}$; the number of scans, 196; and the time constant, $20 \mathrm{~ms}$. To determine $\mathrm{g}_{\text {iso }}$ values, $\mathrm{X}$-band continuous-wave EPR spectra of a mixture of the analyzed radical $(\mathbf{6 a}, \mathbf{6 c}$, or $\mathbf{6 d})$ with TEMPO were recorded. Then, the known $\mathrm{g}_{\text {iso }}$ of TEMPO was used for a spectrum simulation, and the target $g_{\text {iso }}$ value was excluded. Simulations of solution EPR lines were carried out in the Easy Spin software, which is available at www.easyspin.org (accessed on 18 May 2021).

\subsection{Synthesis}

\subsubsection{Imidazo[1,2-b]isoxazoles $\mathbf{2 a}, \mathbf{c}, \mathbf{d}$}

Compounds $\mathbf{2 a , c , d}$ were synthesized via a reaction of 2-hydroxyamino oximes $\mathbf{1 a}, \mathbf{c}, \mathbf{d}$ [44] with acetylacetone [39]. Their ${ }^{1} \mathrm{H}$ NMR spectra and other data are consistent with those described in the literature.

6-Hydroxy-2,3,6,7a-tetramethyl-3,6,7,7a-tetrahydroimidazo[1,2-b]isoxazole 1-oxide (2a) (a mixture of three diastereomers). ${ }^{13} \mathrm{C}$ NMR $\left(150 \mathrm{MHz}, \mathrm{DMSO}-d_{6}\right), \delta, \mathrm{ppm}: 9.8,10.17^{*}, 10.2$ $\left(\mathrm{C}(2)-\mathrm{CH}_{3}\right) ; 12.2,16.8^{*}, 18.5\left(\mathrm{C}(3)-\mathrm{CH}_{3}\right) ; 19.2,23.7^{*}, 24.7,24.8,25.3^{*}, 25.9\left(\mathrm{C}(7 \mathrm{a})-\mathrm{CH}_{3}\right.$ and $\left.\mathrm{C}(6)-\mathrm{CH}_{3}\right) ; 48.9,49.6,50.6^{*}$ (C-7); 62.2, 66.3* 70.5 (C-3); 98.3, 98.9*, 99.2 (C-7a); 100.4, 101.3*, 104.9 (C-6); 137.1, 138.3* 139.3 (C-2). (The asterisk denotes a minor isomer).

2-Hydroxy-2,3a-dimethyl-2,3,3a,5,6,7,8,8a-octahydrobenzo[d]isoxazolo[2,3-a]imidazole 4-oxide (2c) (a mixture of two diastereomers). ${ }^{13} \mathrm{C}$ NMR (75 MHz, DMSO- $\left.d_{6}\right), \delta$, ppm: 23.6, 23.7*, 23.8*, 24.7, 25.2* (C-6, C-7, C-8); 24.7* $24.8,25.1^{*}, 25.6\left(\mathrm{C}(3 \mathrm{a})-\mathrm{CH}_{3}\right.$ and $\left.\mathrm{C}(2)-\mathrm{CH}_{3}\right) ; 32.5^{*}, 34.6(\mathrm{C}-5)$; 48.8, 50.4* (C-3); 69.0* 72.7 (C-8a); 99.6, 100.0* (C-3a); 102.2*, 106.0 (C-2); 140.9*, 141.7 (C-4a); (The asterisk denotes a minor isomer).

2-Hydroxy-2,3a-dimethyl-3,3a,5,6,7,8,9,9a-octahydro-2H-cyclohepta[d]isoxazolo[2,3-a]imidazole 4oxide (2d) (a mixture of six diastereomers). ${ }^{13} \mathrm{C}$ NMR (150 MHz, DMSO- $\left.d_{6}\right), \delta$, ppm: 12.8 , $13.5,18.6^{*}, 18.7,19.9,23.6,24.7,24.9,25.3,25.4,25.96,26.03^{*}\left(\mathrm{C}(3 \mathrm{a})-\mathrm{CH}_{3}\right.$ and $\left.\mathrm{C}(2)-\mathrm{CH}_{3}\right)$; 24.0, 24.2, 24.3, 24.5* 24.7, 25.5, 26.6* , 26.8, 26.9, 27.0, 27.7, 27.8, 27.9, 27.94, 28.7, 28.8, 28.9*, $29.2,30.5^{*}, 30.53,30.58,33.9,34.1,34.8,36.4^{*}$ (C-5, C-6, C-7, C-8, C-9); 48.7, 49.1, 49.8*, 50.6, 56.3 (C-3); 66.7, 68.1* 69.6, 71.2, 75.4, 77.8 (C-9a); 98.3, 98.7, 99.0, 99.6*, 100.7*, 101.7, 102.8, $105.4,105.9,106.8$ (C-3a and C-2); 141.2, 141.6, 142.8* $143.7,144.2,145.3$ (C-4a); (The asterisk denotes the main isomer). 
3.2.2. The General Synthetic Procedure for the Recyclization of Imidazo[1,2-b]isoxazoles

2a,c,d to 8-Hydroxy-5-methyl-3-oxo-6,8-diazabicyclo[3,2,1]-6-octenes 5a,c,d

To a cold solution $\left(0-5{ }^{\circ} \mathrm{C}\right)$ of imidazoisoxazole $2(10 \mathrm{mmol})$ in $10-15 \mathrm{~mL}$ of water, a solution of $10 \mathrm{mmol}$ of $\mathrm{NaOH}$ in $14 \mathrm{~mL}$ of water was added with stirring for $20 \mathrm{~min}$ and was kept on ice for $3 \mathrm{~h}$. The reaction mixture was neutralized with $10 \%$ hydrochloric acid in an ice-water bath, and $\mathrm{NaCl}$ was added until saturation at room temperature. The precipitate of bicycle 5 was filtered off, washed with a small amount of ice-cold water, and dried until constant weight.

8-Hydroxy-1,5,7-trimethyl-6,8-diazabicyclo[3.2.1]oct-6-en-3-one (5a), colorless crystals, isolated yield $0.72 \mathrm{~g}(40 \%)$, m.p. $175-177^{\circ} \mathrm{C}(i-\mathrm{PrOH})$. Elemental analysis: found: $\mathrm{C}, 59.42 ; \mathrm{H}, 7.90$; $\mathrm{N}, 15.45$; calcd. for $\mathrm{C}_{9} \mathrm{H}_{14} \mathrm{~N}_{2} \mathrm{O}_{2}: \mathrm{C}, 59.32 ; \mathrm{H}, 7.74 ; \mathrm{N}, 15.37 \%$. IR spectrum, $v, \mathrm{~cm}^{-1}$, $(\mathrm{KBr})$ : 3124, 2978, 2847, $1714(\mathrm{C}=\mathrm{O}), 1637(\mathrm{C}=\mathrm{N}), 1456,1375,1315,1242 .{ }^{1} \mathrm{H}$ NMR $(400 \mathrm{MHz}$, DMSO-d 6 ), $\delta$, ppm $(J, \mathrm{~Hz})$ : A: Main isomer (keto form): $1.16\left(\mathrm{~s}, 3 \mathrm{H}, \mathrm{CH}_{3}\right) ; 1.29\left(\mathrm{~s}, 3 \mathrm{H}, \mathrm{CH}_{3}\right)$; $1.87\left(\mathrm{~s}, 3 \mathrm{H}, \mathrm{CH}_{3}\right) ; 1.95(\mathrm{~d}, J=4.4,1 \mathrm{H}, \mathrm{CH}) ; 1.99(\mathrm{~d}, J=4.4,1 \mathrm{H}, \mathrm{CH}) ; 2.47(\mathrm{~d}, J=17.0,1 \mathrm{H}$, $\mathrm{CH}) ; 2.57$ (d, J = 17.0, 1H, CH); 8.33 (brs, 1H, N-OH). B: Cyclic hemiacetal: 1.21 (s, 3H, $\left.\mathrm{CH}_{3}\right) ; 1.34\left(\mathrm{~s}, 3 \mathrm{H}, \mathrm{CH}_{3}\right) ; 1.90\left(\mathrm{~s}, 3 \mathrm{H}, \mathrm{CH}_{3}\right) ; 1.49(\mathrm{dd}, J=2.8,11.8,1 \mathrm{H}, \mathrm{CH}) ; 1.57(\mathrm{~d}, J=11.8$, $1 \mathrm{H}, \mathrm{CH}) ; 1.67$ (dd, $J=2.8,11.8,1 \mathrm{H}, \mathrm{CH}) ; 1.80$ (d, J = 11.8, 1H, CH); 7.45 (brs, 1H, C-OH). $\mathrm{C}$ : Minor isomer (keto form): $1.29\left(\mathrm{~s}, 3 \mathrm{H}, \mathrm{CH}_{3}\right) ; 1.41\left(\mathrm{~s}, 3 \mathrm{H}, \mathrm{CH}_{3}\right) ; 1.91\left(\mathrm{~s}, 3 \mathrm{H}, \mathrm{CH}_{3}\right) ; 2.29$ $(\mathrm{dd}, J=2.1,17.3,1 \mathrm{H}, \mathrm{CH}) ; 2.43(\mathrm{dd}, J=2.1,17.3,1 \mathrm{H}, \mathrm{CH}) ; 7.88$ (brs, $1 \mathrm{H}, \mathrm{N}-\mathrm{OH}) .{ }^{13} \mathrm{C}$ NMR (100 MHz, DMSO-d 6 ), $\delta$, ppm: A: Main isomer (keto form): $16.4\left(\mathrm{CH}_{3}\right) ; 18.8\left(\mathrm{CH}_{3}\right) ; 23.1$ $\left(5-\mathrm{CH}_{3}\right) ; 40.7\left(\mathrm{CH}_{2}\right) ; 42.0\left(\mathrm{CH}_{2}\right) ; 69.8(\mathrm{C}-1) ; 85.8(\mathrm{C}-5) ; 177.8(\mathrm{C}=\mathrm{N}) ; 206.9(\mathrm{C}=\mathrm{O})$. B: Cyclic hemiacetal: $16.7\left(\mathrm{CH}_{3}\right) ; 21.5\left(\mathrm{CH}_{3}\right) ; 25.8\left(5-\mathrm{CH}_{3}\right) ; 44.5\left(\mathrm{CH}_{2}\right) ; 45.9\left(\mathrm{CH}_{2}\right) ; 76.1(\mathrm{C}-1)$; 93.6 (C-5); $114.0(\mathrm{NOCO}) ; 177.3(\mathrm{C}=\mathrm{N})$. C: Minor isomer (keto form): $16.4\left(\mathrm{CH}_{3}\right) ; 17.1\left(\mathrm{CH}_{3}\right)$; $21.3\left(\mathrm{CH}_{3}\right) ; 49.0\left(\mathrm{CH}_{2}\right) ; 50.3\left(\mathrm{CH}_{2}\right) ; 75.1(\mathrm{C}-1)$; $90.6(\mathrm{C}-5) ; 175.1(\mathrm{C}=\mathrm{N}) ; 205.8(\mathrm{C}=\mathrm{O})$.

8-Hydroxy-5-methyl-1,7-tetramethylene-6,8-diazabicyclo[3.2.1]oct-6-en-3-one (5c), colorless rhombic crystals, isolated yield $1.04 \mathrm{~g}(50 \%)$, m.p. $188-190{ }^{\circ} \mathrm{C}$ (abs EtOH). Elemental analysis: found: $\mathrm{C}, 63.50 ; \mathrm{H}, 7.90 ; \mathrm{N}, 13.33$; calcd. for $\mathrm{C}_{11} \mathrm{H}_{16} \mathrm{~N}_{2} \mathrm{O}_{2}$ : C, 63.44; $\mathrm{H}, 7.74 ; \mathrm{N}, 13.45 \%$. IR spectrum, v, $\mathrm{cm}^{-1}$, (KBr): 3402, 3099, 2941, 2862, 1715 (C=O), 1639 (C=N), 1452, 1313, 1238, 1009, 955, 812. ${ }^{1} \mathrm{H}$ NMR (600 MHz, DMSO-d 6 ), $\delta$, ppm (J, Hz): A: Main isomer (keto form): 1.25-1.87 (m, 6H, $\left.\left(\mathrm{CH}_{2}\right)_{3}\right) ; 1.30$ (s, 3H, Me); $1.91(\mathrm{~d}, J=12.0,1 \mathrm{H}, \mathrm{CH}) ; 1.97(\mathrm{~d}, J=12.0,1 \mathrm{H}$, $\mathrm{CH})$; 2.14-2.70 (m, 2H, 2CH); 2.49 (d, $J=12.0,1 \mathrm{H}, \mathrm{CH}) ; 2.56(\mathrm{~d}, J=12.0,1 \mathrm{H}, \mathrm{CH}) ; 8.29$ (brs, 1H, N-OH). B: Cyclic hemiacetal: 1.25-1.87 (m, 10H, $\left(\mathrm{CH}_{2}\right)_{3}$ and $\left.\mathrm{CH}_{2} \mathrm{COCH}_{2}\right) ; 1.37(\mathrm{~s}, 3 \mathrm{H}$, $\mathrm{Me}) ; 2.12-2.70(\mathrm{~m}, 2 \mathrm{H}, 2 \mathrm{CH}) ; 7.54(\mathrm{~s}, 1 \mathrm{H}, \mathrm{C}-\mathrm{OH})$. C: Minor isomer (keto form): 1.25-1.87 (m, $\left.6 \mathrm{H},\left(\mathrm{CH}_{2}\right)_{3}\right) ; 1.45\left(\mathrm{~s}, 3 \mathrm{H}, \mathrm{CH}_{3}\right) ; 2.14-2.32(\mathrm{~m}, 3 \mathrm{H}, 3 \mathrm{CH}) ; 2.43(\mathrm{~d}, J=18.0,1 \mathrm{H}, \mathrm{CH}) ; 2.57(\mathrm{~d}$, $J=18.0,1 \mathrm{H}, \mathrm{CH}) ; 2.60-2.70(\mathrm{~m}, 1 \mathrm{H}, \mathrm{CH}) ; 7.89$ (brs, 1H, N-OH). D: tetrahydropyridone 3c (as an impurity): $1.25-2.25\left(\mathrm{~m}, 8 \mathrm{H},\left(\mathrm{CH}_{2}\right)_{4}\right) ; 1.88\left(\mathrm{~s}, 3 \mathrm{H}, \mathrm{CH}_{3}\right) ; 2.16\left(\mathrm{~d}, J_{A B}=18.0,1 \mathrm{H}, \mathrm{CH}\right) ; 2.49$ $\left(\mathrm{d}, J_{A B}=18.0,1 \mathrm{H}, \mathrm{CH}\right) ; 4.57(\mathrm{~s}, 1 \mathrm{H}, \mathrm{CH}=) ; 7.27(\mathrm{~s}, 1 \mathrm{H}, \mathrm{NH}) ; 10.75(\mathrm{~s}, 1 \mathrm{H},=\mathrm{NOH}) .{ }^{13} \mathrm{C}$ NMR (150 MHz, DMSO- $\left.d_{6}\right), \delta$, ppm: A: Main isomer (keto form): 23.0 (Me); 21.0, 24.3; 29.2, 34.5 $\left(\left(\mathrm{CH}_{2}\right)_{4}\right) ; 42.5,46.2\left(\mathrm{CH}_{2}-\mathrm{C}=\mathrm{O}\right) ; 68.9(\mathrm{~N}-\mathrm{C}-\mathrm{C}=\mathrm{N}) ; 85.9(\mathrm{~N}-\mathrm{C}-\mathrm{N}) ; 178.7(\mathrm{C}=\mathrm{N}) ; 207.0(\mathrm{C}=\mathrm{O})$. B: Cyclic hemiacetal: $25.7\left(\mathrm{CH}_{3}\right) ; 21.6,24.2,29.7,36.9\left(\left(\mathrm{CH}_{2}\right)_{4}\right) ; 44.0,44.8\left(\mathrm{CH}_{2}-\mathrm{C}=\mathrm{O}\right) ; 76.2$ $(\mathrm{N}-\mathrm{C}-\mathrm{C}=\mathrm{N}) ; 94.2(\mathrm{~N}-\mathrm{C}-\mathrm{N}) ; 114.1(\mathrm{NOCO}) ; 178.2(\mathrm{C}=\mathrm{N})$. C: Minor isomer (keto form): 21.5 (Me); 21.2, 24.9, 28.2, $29.0\left(\left(\mathrm{CH}_{2}\right)_{4}\right) ; 48.2,50.3\left(\mathrm{CH}_{2}-\mathrm{C}=\mathrm{O}\right) ; 74.9(\mathrm{~N}-\mathrm{C}-\mathrm{C}=\mathrm{N}) ; 91.0(\mathrm{~N}-\mathrm{C}-\mathrm{N})$; $175.7(\mathrm{C}=\mathrm{N}) ; 205.8(\mathrm{C}=\mathrm{O})$. D: tetrahydropyridone 3c (as an impurity): $20.6\left(\mathrm{CH}_{3}\right) ; 20.1,20.4$, 25.4, $38.2\left(\left(\mathrm{CH}_{2}\right)_{4}\right)$; 44.8 (C-5); 58.6 (C-6); 96.9 (C-3); 156.9, 160.4 (C-2 and C-7); 190.0 (C-4).

8-Hydroxy-5-methyl-1,7-pentamethylene-6,8-diazabicyclo[3.2.1]oct-6-en-3-one (5d), colorless rhombic crystals, isolated yield $1.11 \mathrm{~g}$ (50\%), m.p. 203-204 ${ }^{\circ} \mathrm{C}$ (abs EtOH). Elemental analysis: found: $\mathrm{C}, 65.10 ; \mathrm{H}, 8.31 ; \mathrm{N}, 12.62$; calcd. for $\mathrm{C}_{12} \mathrm{H}_{18} \mathrm{~N}_{2} \mathrm{O}_{2}$ : C, 64.84; $\mathrm{H}, 8.16 ; \mathrm{N}$, $12.60 \%$. IR spectrum, $v, \mathrm{~cm}^{-1}$, (KBr): 3400, 3093, 2926, 2852, $1716(\mathrm{C}=\mathrm{O}), 1630(\mathrm{C}=\mathrm{N}), 1448$,

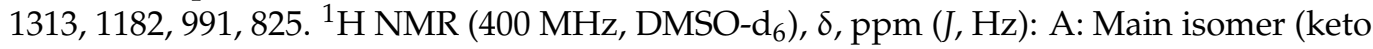
form): $1.06-1.90\left(\mathrm{~m}, 8 \mathrm{H},\left(\mathrm{CH}_{2}\right)_{4}\right) ; 1.30(\mathrm{~s}, 3 \mathrm{H}, \mathrm{Me}) ; 1.94(\mathrm{~d}, J=16.0,1 \mathrm{H}, \mathrm{CH}) ; 2.00(\mathrm{~d}, J=16.0$, $1 \mathrm{H}, \mathrm{CH}) ; 2.17-2.42(\mathrm{~m}, 2 \mathrm{H}, 2 \mathrm{CH}) ; 2.46(\mathrm{~d}, J=16.0,1 \mathrm{H}, \mathrm{CH}) ; 2.61(\mathrm{~d}, J=16.0,1 \mathrm{H}, \mathrm{CH}) ; 8.28$ 
(brs, $1 \mathrm{H}, \mathrm{N}-\mathrm{OH})$. B: Cyclic hemiacetal: 1.06-1.90 (m, 12H, $\left(\mathrm{CH}_{2}\right)_{4}$ and $\left.\mathrm{CH}_{2} \mathrm{COCH}_{2}\right) ; 1.34$ (s, 3H, Me); $2.17-2.42$ (m, 2H, 2CH); 7.51 (brs, 1H, C-OH). ${ }^{13} \mathrm{C} \mathrm{NMR} \mathrm{(100} \mathrm{MHz,} \mathrm{DMSO-d} 6$ ), $\delta$, ppm: A: Main isomer (keto form): $23.4\left(\mathrm{CH}_{3}\right) ; 23.4,28.4,30.7,32.0,32.1\left(\left(\mathrm{CH}_{2}\right)_{5}\right) ; 41.2,42.8$ $\left(\mathrm{CH}_{2}-\mathrm{C}=\mathrm{O}\right) ; 73.5(\mathrm{~N}-\mathrm{C}-\mathrm{C}=\mathrm{N}) ; 85.9(\mathrm{~N}-\mathrm{C}-\mathrm{N}) ; 182.2(\mathrm{C}=\mathrm{N}) ; 207.3(\mathrm{C}=\mathrm{O})$. B: Cyclic hemiacetal: $26.0\left(\mathrm{CH}_{3}\right) ; 24.3,27.8,32.1,32.5,35.4\left(\left(\mathrm{CH}_{2}\right)_{5}\right) ; 44.5,46.2\left(\mathrm{CH}_{2}-\mathrm{C}=\mathrm{O}\right) ; 80.1(\mathrm{~N}-\mathrm{C}-\mathrm{C}=\mathrm{N}) ; 93.8$ $(\mathrm{N}-\mathrm{C}-\mathrm{N}) ; 113.9(\mathrm{NOCO}) ; 181.9(\mathrm{C}=\mathrm{N})$.

3.2.3. The General Procedure for the Oxidation of 8-Hydroxy-6,8-diazabicyclo[3.2.1]oct6-en-3-ones $\mathbf{5 a , c , d}$

An amount of 8-hydroxydiazabicyclooctene $5(0.55 \mathrm{mmol})$ was stirred in $10 \mathrm{~mL}$ of acetone for $5 \mathrm{~min}$; after that, $2.0 \mathrm{mmol}$ of $\mathrm{PbO}_{2}$ was added, and the suspension was stirred for $3 \mathrm{~h}$ at room temperature and passed through a fine pore glass filter, and the precipitate was washed thoroughly with $\mathrm{Me}_{2} \mathrm{CO}(3 \times 5 \mathrm{~mL})$. Combined filtrates were evaporated, and the solid residue was diluted with $2 \mathrm{~mL}$ of EtOAc and flash chromatographed with an ethyl acetate on a column with silica to obtain a colored fraction containing radical 6 . The solvent was evaporated, the residue was treated with cold hexane, and the precipitate of NR 6 was filtered off.

1,5,7-Trimethyl-6,8-diazabicyclo[3.2.1]oct-6-en-3-one 8-oxyl (6a). Light purple fine crystals, isolated yield $81 \mathrm{mg}(81 \%)$, m.p. $66-68{ }^{\circ} \mathrm{C}$ (hexane), $R_{f} 0.45$ (EtOAc). Elemental analysis: found: $\mathrm{C}, 59.42 ; \mathrm{H}, 7.60 ; \mathrm{N}, 15.41$; calcd. for $\mathrm{C}_{9} \mathrm{H}_{13} \mathrm{~N}_{2} \mathrm{O}_{2}: \mathrm{C}, 59.65 ; \mathrm{H}, 7.23 ; \mathrm{N}, 15.46 \%$. IR spectrum, $v, \mathrm{~cm}^{-1}$, (KBr): 2991, 2937, 2893, $1718(\mathrm{C}=\mathrm{O}), 1626(\mathrm{C}=\mathrm{N}), 1450,1371,1313$, 1236. UV (EtOH), $\lambda_{\max } \mathrm{nm},(\lg \varepsilon): 298$ (2.65), 312 (2.65). High-resolution mass spectrometry (HRMS), electrospray ionization (EI): Observed 181.0970; $\mathrm{C}_{9} \mathrm{H}_{13} \mathrm{~N}_{2} \mathrm{O}_{2}\left([\mathrm{M}]^{+}\right)$; calculated 181.0972. ESR (PhMe): br. triplet; $\mathrm{a}_{\mathrm{N} 1}=1.852 \mathrm{mT} ; \mathrm{g}_{\text {iso }}=2.0054$.

5-Methyl-1,7-tetramethylene-6,8-diazabicyclo[3.2.1]oct-6-en-3-one 8-oxyl (6c). Purple needle crystals, isolated yield $92 \mathrm{mg}(81 \%)$, m.p. $102-104{ }^{\circ} \mathrm{C}$ (hexane), $R_{f} 0.45$ (EtOAc). Elemental analysis: found: $\mathrm{C}, 63.55 ; \mathrm{H}, 7.31 ; \mathrm{N}, 13.30$; calcd. for $\mathrm{C}_{11} \mathrm{H}_{15} \mathrm{~N}_{2} \mathrm{O}_{2}$ : $\mathrm{C}, 63.75 ; \mathrm{H}, 7.30 ; \mathrm{N}$, 13.52\%. IR spectrum, $v, \mathrm{~cm}^{-1}$, (KBr): 2951, 2862, $1716(\mathrm{C}=\mathrm{O}), 1628(\mathrm{C}=\mathrm{N}), 1448,1392,1373$, 1317, 1238, 1167. UV (EtOH), $\lambda_{\max } \mathrm{nm},(\lg \varepsilon): 235$ (3.30). HRMS (EI): Observed 207.1126; $\mathrm{C}_{11} \mathrm{H}_{15} \mathrm{~N}_{2} \mathrm{O}_{2}\left([\mathrm{M}]^{+}\right)$; calculated 207.1126. ESR $(\mathrm{PhMe}): \mathrm{a}_{\mathrm{N} 1}=1.855 \mathrm{mT} ; \mathrm{a}_{\mathrm{H} 1}=0.217 \mathrm{mT}$; $\mathrm{a}_{\mathrm{H} 2}=0.1798 \mathrm{mT} ; \mathrm{a}_{\mathrm{H} 3}=0.119 \mathrm{mT} ; \mathrm{a}_{\mathrm{H} 4}=0.095 \mathrm{mT} ; \mathrm{a}_{\mathrm{H} 5, \mathrm{H} 6, \mathrm{H} 7}=0.041 \mathrm{mT} ; \mathrm{a}_{\mathrm{H} 8}=0.054 \mathrm{mT}$; $\mathrm{a}_{\mathrm{H} 9}=0.025 \mathrm{mT} ; \mathrm{a}_{\mathrm{H} 10}=0.022 \mathrm{mT} ; \mathrm{a}_{\mathrm{H} 11}=0.019 \mathrm{mT} ; \mathrm{a}_{\mathrm{H} 12}=0.015 \mathrm{mT} ; \mathrm{a}_{\mathrm{N} 2}=0.009 \mathrm{mT}$; $\mathrm{a}_{\mathrm{H} 13}=0.004 \mathrm{mT} ; \mathrm{a}_{\mathrm{H} 14}=0.002 \mathrm{mT} ; \mathrm{a}_{\mathrm{H} 15}=0.001 \mathrm{mT} ; \mathrm{g}_{\text {iso }}=2.00664$.

5-Methyl-1,7-pentamethylene-6,8-diazabicyclo[3.2.1]oct-6-en-3-one-8-oxyl (6d). Dark purple needles, isolated yield $106 \mathrm{mg}(87 \%)$, m.p. $98-100{ }^{\circ} \mathrm{C}$ (hexane), $R_{f} 0.45$ (EtOAc). Elemental analysis: found: $\mathrm{C}, 65.22 ; \mathrm{H}, 8.01 ; \mathrm{N}, 12.57$; calcd. for $\mathrm{C}_{12} \mathrm{H}_{17} \mathrm{~N}_{2} \mathrm{O}_{2}$ : $\mathrm{C}, 65.14 ; \mathrm{H}, 7.74 ; \mathrm{N}$, $12.66 \%$. IR spectrum, $v, \mathrm{~cm}^{-1},(\mathrm{KBr}): 2941,2929,2856,1722$ and $1711(\mathrm{C}=\mathrm{O}), 1616(\mathrm{C}=\mathrm{N})$, 1446, 1383, 1313, 1317, 1227, 1182. UV (EtOH), $\lambda_{\max } \mathrm{nm},(\lg \varepsilon): 238$ (3.30). HRMS (EI): Observed 221.1286; $\mathrm{C}_{12} \mathrm{H}_{17} \mathrm{~N}_{2} \mathrm{O}_{2}\left([\mathrm{M}]^{+}\right)$; calculated 221.1285. ESR (PhMe): br. triplet; $\mathrm{a}_{\mathrm{N} 1}=1.841 \mathrm{mT} ; \mathrm{g}_{\text {iso }}=2.00667$.

\subsubsection{The General Procedure for the Reduction of NRs $\mathbf{6 a}, \mathbf{c}, \mathbf{d}$}

To a stirred solution of nitroxide $6(1.89 \mathrm{mmol})$ in $15 \mathrm{~mL}$ of acetone, zinc powder $(123 \mathrm{mg}, 1.89 \mathrm{mmol})$ was added, followed by dropwise addition of a solution of $\mathrm{NH}_{4} \mathrm{Cl}$ (158 mg, $2.27 \mathrm{mmol}$ ) in $1 \mathrm{~mL}$ of water during $15 \mathrm{~min}$. The mixture was incubated for $25 \mathrm{~min}$, the precipitate was filtered off, and the filtrate was evaporated. The residue was treated with cold water, and the precipitate was filtered off, washed with a minimal amount of water and diethyl ether, and dried until constant weight. The yield of bicyclic hydroxylamine 5 depends on its solubility in water and varies from $48 \%$ (for compound 5a) up to $79 \%$ (for $\mathbf{5 d}$ ). IR spectra of the obtained compounds are consistent with the IR spectra of those synthesized through the recyclization of 2 . 
3.2.5. Base-Promoted Recyclization of 8-Hydroxy-6,8-diazabicyclo[3.2.1]oct-6-en-3-one 5d into Tetrahydropyridine-4-one $\mathbf{3 d}$

A solution of $21 \mathrm{mg}(0.525 \mathrm{mmol})$ of $\mathrm{NaOH}$ in $1 \mathrm{~mL}$ of water was added to a suspension of $111 \mathrm{mg}(0.5 \mathrm{mmol})$ of bicycle $5 \mathrm{~d}$ in $1 \mathrm{~mL}$ of water, and the resulting solution was stirred at $65^{\circ} \mathrm{C}$ for $150 \mathrm{~min}$. The reaction mixture was cooled to ambient temperature, neutralized with $10 \%$ aq $\mathrm{HCl}$ and kept at $3{ }^{\circ} \mathrm{C}$ for $15 \mathrm{~h}$. The precipitate of $3 \mathrm{~d}$ was filtered off, washed with $1 \mathrm{~mL}$ of ice water, and dried to constant weight. The aqueous filtrate was saturated with $\mathrm{NaCl}$ and kept at room temperature for $2 \mathrm{~d}$; the precipitate was filtered off and washed with a minimal volume of ice water to isolate an additional amount of $\mathbf{3 d}$.

7-(Hydroxyimino)-2-methyl-1-azaspiro[5.6]dodec-2-en-4-one (3d). Pale fine crystal powder, total isolated yield $84 \mathrm{mg}(76 \%)$. Its IR and ${ }^{1} \mathrm{H}$ NMR spectra are consistent with those described in the literature [39]. ${ }^{13} \mathrm{C}$ NMR $\left(75 \mathrm{MHz}, \mathrm{DMSO}-d_{6}\right), \delta, \mathrm{ppm}: 20.5\left(\mathrm{CH}_{3}\right) ; 22.9$ (C-11); 23.3 (C-8); 25.7 (C-9); 30.3 (C-10); 39.3 (C-12); 44.9 (C-5); 61.5 (C-6); 96.8 (C-3); 159.2, 159.8 (C-2 and C-7); 190.2 (C-4).

\section{Conclusions}

It was shown in this work that imidazo[1,2-b]isoxazoles formed by the reaction of acetylacetone with 2-hydroxyaminooximes having a secondary hydroxyamino group are key compounds for the synthesis of sterically hindered hydroxylamines, precursors of the corresponding BNRs containing two functional groups in a paramagnetic molecule. It should be pointed out that these nitroxides simultaneously contain TEMPON and 3imidazoline frames in the molecular core; this dualism may open up new possibilities for the synthesis of functional DNP agents, radical polymerization mediators, catalysts of one-electron oxidation, spin-labeled chelating ligands, and other constructs. Being aza-analogs of NRs of the nortropinone series, radicals 6 can become convenient starting compounds for the synthesis of polyfunctional hydrophilic nitroxides of the 3-imidazoline series (cf. [45]).

Considering the increased interest of researchers in BNRs as promising agents for the oxidation of various alcohols, amines, and related compounds (including sterically hindered ones), further work is being planned regarding the synthesis, reactivity evaluation, transformation of the keto function, and determination of electrochemical characteristics of BNRs of the 6,8-diazabicyclo [3.2.1]-6-octene 8-oxyls series.

Supplementary Materials: The following are available online: IR, NMR, and mass spectra data for bicycles $\mathbf{5}$ and for BRNs $\mathbf{6}$ as well as $h f c$ constants for the EPR spectrum of $\mathbf{6 c}$.

Author Contributions: Conceptualization, A.Y.T. and L.N.G.; methodology, A.Y.T., L.N.G. and D.G.M.; validation, K.A.L. and L.N.G.; formal analysis, A.Y.T. and D.G.M.; investigation, L.N.G., A.Y.T., K.A.L. and D.G.M.; writing - original draft preparation, L.N.G., A.Y.T. and D.G.M.; writingreview and editing, D.G.M. and A.Y.T.; supervision, D.G.M. All authors have read and agreed to the published version of the manuscript.

Funding: This research was funded by the Ministry of Science and Higher Education of Russia (project number 14.W03.31.0034).

Institutional Review Board Statement: Not applicable.

Informed Consent Statement: Not applicable.

Data Availability Statement: Not applicable.

Acknowledgments: We thank the Multi-Access Chemical Research Center SB RAS for spectral and analytical measurements.

Conflicts of Interest: The authors declare no conflict of interest.

Sample Availability: Samples of compounds $\mathbf{5 a}, \mathbf{c}, \mathbf{d}$ and $\mathbf{6 a}, \mathbf{c}, \mathbf{d}$ are available from the authors (A.Y.T. or D.G.M.) upon request. 


\section{References}

1. Volodarsky, L.B.; Reznikov, V.A.; Ovcharenko, V.I. Synthetic Chemistry of Stable Nitroxides; CRC Press: Boca Raton, FL, USA, 1994; pp. 1-240.

2. Volodarsky, L.B.; Grigor'ev, I.A.; Dikanov, S.A.; Reznikov, V.A.; Shchukin, G.I. Imidazoline Nitroxides. Synthesis and Properties; CRC Press: Boca Raton, FL, USA, 1988; Volume 1, pp. 1-222.

3. Keana, J.F.W. Newer aspects of the synthesis and chemistry of nitroxide spin labels. Chem. Rev. 1978, 78, 37-64. [CrossRef]

4. Karoui, H.; Le Moigne, F.; Ouari, O.; Tordo, P. Nitroxide Radicals: Properties, Synthesis and Applications. In Stable Radicals: Fundamentals and Applied Aspects of Odd-Electron Compounds; Hicks, R.G., Ed.; John Wiley \& Sons: Hoboken, NJ, USA, 2010; pp. 173-229. [CrossRef]

5. Tretyakov, E.V.; Ovcharenko, V.I. The chemistry of nitroxide radicals in the molecular design of magnets. Russ. Chem. Rev. 2009, 78, 971-1012. [CrossRef]

6. Haugland, M.M.; Lovett, J.E.; Anderson, E.A. Advances in the synthesis of nitroxide radicals for use in biomolecule spin labelling. Chem. Soc. Rev. 2018, 47, 668-680. [CrossRef] [PubMed]

7. Bognar, B.; Ur, G.; Sar, C.; Hankovszky, O.H.; Hideg, K.; Kalai, T. Synthesis and Application of Stable Nitroxide Free Radicals Fused with Carbocycles and Heterocycles. Curr. Org. Chem. 2019, 23, 480-501. [CrossRef]

8. Zaytseva, E.V.; Mazhukin, D.G. Spirocyclic Nitroxides as Versatile Tools in Modern Natural Sciences: From Synthesis to Applications. Part I. Old and New Synthetic Approaches to Spirocyclic Nitroxyl Radicals. Molecules 2021, 26, 677. [CrossRef] [PubMed]

9. Kirilyuk, I.A.; Mazhukin, D.G. General Approaches to Synthesis of Nitroxides. In Nitroxides: Synthesis, Properties and Applications; Ouari, O., Gigmes, D., Eds.; The Royal Society of Chemistry: Cambridge, UK, 2021; pp. 7-70.

10. Tebben, L.; Studer, A. Nitroxides: Applications in Synthesis and in Polymer Chemistry. Angew. Chem. Int. Ed. 2011, 50, 5034-5068. [CrossRef]

11. Ma, Z.; Mahmudov, K.T.; Aliyeva, V.A.; Gurbanov, A.V.; Pombeiro, A.J.L. TEMPO in metal complex catalysis. Coord. Chem. Rev. 2020, 423, 213482. [CrossRef]

12. Bagryanskaya, E.G.; Marque, S.R.A. Scavenging of Organic C-Centered Radicals by Nitroxides. Chem. Rev. 2014, 114, 5011-5056. [CrossRef]

13. Khramtsov, V.V.; Zweier, J.L. Functional in vivo EPR Spectroscopy and Imaging Using Nitroxide and Trityl Radicals. In Stable Radicals: Fundamentals and Applied Aspects of Odd-Electron Compounds; Hicks, R.G., Ed.; John Wiley \& Sons: Hoboken, NJ, USA, 2010; pp. 537-566. [CrossRef]

14. Bardelang, D.; Hardy, M.; Ouari, O.; Tordo, P. Spin Labels and Spin Probes. In Encyclopedia of Radicals in Chemistry, Biology and Materials; Chatgilialoglu, C., Studer, A., Eds.; Wiley, 2012; pp. 1-51. Available online: https:/ / onlinelibrary.wiley.com/doi/abs/ 10.1002/9781119953678.rad081 (accessed on 19 May 2021).

15. Likhtenshtein, G.I. Nitroxides: Brief. History, Fundamentals, and Recent Developments; Springer: Cham, Switzerland, 2020; pp. 1-316. [CrossRef]

16. Likhtenshtein, G.I.; Yamauchi, J.; Nakatsuji, S.; Smirnov, A.I.; Tamura, R. Nitroxides: Applications in Chemistry, Biomedicine and Material Science; Wiley: Weinheim, Germany, 2008; pp. 1-419.

17. Koike, T.; Yasu, Y.; Akita, M. Visible-light-driven Oxidation of 1,3-Dicarbonyl Compounds via Catalytic Disproportionation of TEMPO by Photoredox Catalysis. Chem. Lett. 2012, 41, 999-1001. [CrossRef]

18. Gentry, E.C.; Rono, L.J.; Hale, M.E.; Matsuura, R.; Knowles, R.R. Enantioselective Synthesis of Pyrroloindolines via Noncovalent Stabilization of Indole Radical Cations and Applications to the Synthesis of Alkaloid Natural Products. J. Am. Chem. Soc. 2018, 140, 3394-3402. [CrossRef]

19. Liang, K.; Tong, X.; Li, T.; Shi, B.; Wang, H.; Yan, P.; Xia, C. Enantioselective Radical Cyclization of Tryptamines by Visible Light-Excited Nitroxides. J. Org. Chem. 2018, 83, 10948-10958. [CrossRef]

20. Chen, N.; Xu, H.-C. Electrochemical generation of nitrogen-centered radicals for organic synthesis. Green Synth. Catal. 2021, 2. [CrossRef]

21. Siu, J.C.; Parry, J.B.; Lin, S. Aminoxyl-Catalyzed Electrochemical Diazidation of Alkenes Mediated by a Metastable Charge-Transfer Complex. J. Am. Chem. Soc. 2019, 141, 2825-2831. [CrossRef]

22. Graetz, B.; Rychnovsky, S.; Leu, W.-H.; Farmer, P.; Lin, R. $\mathrm{C}_{2}$-Symmetric nitroxides and their potential as enantioselective oxidants. Tetrahedron Asymmetry 2005, 16, 3584-3598. [CrossRef]

23. Steves, J.E.; Stahl, S.S. Copper(I)/ABNO-Catalyzed Aerobic Alcohol Oxidation: Alleviating Steric and Electronic Constraints of $\mathrm{Cu} / \mathrm{TEMPO}$ Catalyst Systems. J. Am. Chem. Soc. 2013, 135, 15742-15745. [CrossRef] [PubMed]

24. Ryland, B.L.; McCann, S.D.; Brunold, T.C.; Stahl, S.S. Mechanism of Alcohol Oxidation Mediated by Copper(II) and Nitroxyl Radicals. J. Am. Chem. Soc. 2014, 136, 12166-12173. [CrossRef]

25. Rafiee, M.; Miles, K.C.; Stahl, S.S. Electrocatalytic Alcohol Oxidation with TEMPO and Bicyclic Nitroxyl Derivatives: Driving Force Trumps Steric Effects. J. Am. Chem. Soc. 2015, 137, 14751-14757. [CrossRef]

26. Hickey, D.P.; Schiedler, D.A.; Matanovic, I.; Doan, P.V.; Atanassov, P.; Minteer, S.D.; Sigman, M.S. Predicting Electrocatalytic Properties: Modeling Structure-Activity Relationships of Nitroxyl Radicals. J. Am. Chem. Soc. 2015, 137, 16179-16186. [CrossRef]

27. Kim, J.; Stahl, S.S. Cu/Nitroxyl-Catalyzed Aerobic Oxidation of Primary Amines into Nitriles at Room Temperature. ACS Catal. 2013, 3, 1652-1656. [CrossRef] 
28. Xie, X.; Stahl, S.S. Efficient and Selective Cu/Nitroxyl-Catalyzed Methods for Aerobic Oxidative Lactonization of Diols. J. Am. Chem. Soc. 2015, 137, 3767-3770. [CrossRef]

29. Wang, F.; Rafiee, M.; Stahl, S.S. Electrochemical Functional-Group-Tolerant Shono-type Oxidation of Cyclic Carbamates Enabled by Aminoxyl Mediators. Angew. Chem. Int. Ed. 2018, 57, 6686-6690. [CrossRef] [PubMed]

30. Anthony, D.; Lin, Q.; Baudet, J.; Diao, T. Nickel-Catalyzed Asymmetric Reductive Diarylation of Vinylarenes. Angew. Chem. Int. Ed. 2019, 58, 3198-3202. [CrossRef] [PubMed]

31. Lennox, A.J.J.; Goes, S.L.; Webster, M.P.; Koolman, H.F.; Djuric, S.W.; Stahl, S.S. Electrochemical Aminoxyl-Mediated $\alpha$-Cyanation of Secondary Piperidines for Pharmaceutical Building Block Diversification. J. Am. Chem. Soc. 2018, 140, 11227-11231. [CrossRef]

32. Dupeyre, R.-M.; Rassat, A. Nitroxides. XIX. Norpseudopelletierine-N-oxyl, a New, Stable, Unhindered Free Radical. J. Am. Chem. Soc. 1966, 88, 3180-3181. [CrossRef]

33. Rassat, A.; Rey, P. Nitroxides: Photochemical Synthesis of Trimethylisoquinuclidine N-Oxyl. Chem. Commun. 1971, 1161-1162. [CrossRef]

34. Mendenhall, G.D.; Ingold, K.U. Reactions of Bicyclic Nitroxides Involving Reduction of the NO Group. J. Am. Chem. Soc. 1973, 95, 6395-6400. [CrossRef]

35. Rassat, A.; Ronzaud, J. Nitroxydes-LXXI. Synthese de derives nitroxydes du tropane. Etude par RPE et RMN des interactions hyperfines a longue distance dans ces radicaux. Tetrahedron 1976, 32, 239-244. [CrossRef]

36. Shibuya, M.; Tomizawa, M.; Sasano, Y.; Iwabuchi, Y. An Expeditious Entry to 9-Azabicyclo[3.3.1]nonane N-Oxyl (ABNO): Another Highly Active Organocatalyst for Oxidation of Alcohols. J. Org. Chem. 2009, 74, 4619-4622. [CrossRef]

37. Shibuya, M.; Tomizawa, M.; Suzuki, I.; Iwabuchi, Y. 2-Azaadamantane N-Oxyl (AZADO) and 1-Me-AZADO: Highly Efficient Organocatalysts for Oxidation of Alcohols. J. Am. Chem. Soc. 2006, 128, 8412-8413. [CrossRef]

38. Hayashi, M.; Sasano, Y.; Nagasawa, S.; Shibuya, M.; Iwabuchi, Y. 9-Azanoradamantane N-Oxyl (Nor-AZADO): A Highly Active Organocatalyst for Alcohol Oxidation. Chem. Pharm. Bull. 2011, 59, 1570-1573. [CrossRef]

39. Grigor'eva, L.N.; Tikhonov, A.Y.; Martin, V.V.; Volodarskii, L.B. Condensation of 1,2-hydroxylaminooximes with acetylacetone. Conversion of tetrahydroimidazo[1,2-b]isoxazoles into derivatives of $2 H$-imidazole, 1-hydroxypyrrole, and 4-oxotetrahydropyridine. Chem. Heterocycl. Compd. 1990, 26, 637-642. [CrossRef]

40. Ota, T.; Masuda, S.; Tanaka, H. Cyclodimerization of 3-Methyl-3-buten-2-one Oxime. Chem. Lett. 1981, 10, 411-414. [CrossRef]

41. Ota, T.; Masuda, S.; Tanaka, H.; Kido, M. Studies on the Polymerization of Acrolein Oxime. XVI. Structure of 8-Hydroxy-1,4,5,7tetramethyl-6,8-diazabicyclo[3.2.1]oct-6-ene 6-Oxide. Bull. Chem. Soc. Jpn. 1982, 55, 171-173. [CrossRef]

42. Schulz, M.; Mögel, L.; Römbach, J. Zur Ring-Ketten-Tautomerie und Reaktionen eines bicyclischen 1-Hydroxy-3-imidazolin-3oxids. J. Prakt. Chem. 1986, 328, 589-596. [CrossRef]

43. Reinhardt, M.; Schulz, M.; Römbach, J. Radikalabfang. III. [1] ESR-spektroskopische Untersuchung von Radikalreaktionen eines bicyclischen 1 -Hydroxy-3-imidazolin-3-oxids [2]. J. Prakt. Chem. 1986, 328, 597-602. [CrossRef]

44. Grigor'eva, L.N.; Volodarskii, L.B.; Tikhonov, A.Y. Preparation of aliphatic $\alpha$-(hydroxyamino) oximes by reaction of $\alpha$-halo ketones with hydroxylamine. Izv. Sib. Otd. AN SSSR Ser. Khim. 1989, 3, 125-126.

45. Keana, J.F.W.; Heo, G.S.; Gaughan, G.T. Stereospecific Synthesis of Difunctionalized 2,5-Disubstituted cis-2,5-Dimethylpyrrolidine (Azethoxyl) Nitroxides by Oxidative Cleavage of Protected 8-Azabicyclo[3.2.1]octane Precursors. J. Org. Chem. 1985, 50, 2351. [CrossRef] 